\title{
Solid-phase extraction gold from alkaline cyanide solution with quaternary ammonium surfactant
}

\author{
Run-Fang Xie, Qiu-Fen Hu, Guang-Yu Yang, \\ Jing Chen, Yun-Shan Han, Yong-He Zhao, \\ Zhen $\mathrm{Li}^{*}$
}

Received: 27 September 2013/Revised: 27 October 2013/Accepted: 21 May 2014/Published online: 5 July 2014

(C) The Author(s) 2014. This article is published with open access at Springerlink.com

\begin{abstract}
The solid-phase extraction (SPE) technique applied to the extraction of organic compound was creatively used as the extraction of inorganic gold in the paper. Two types of techniques were proposed and explored, namely the SPE and the liquid-liquid extraction (LLE) of the quaternary ammonium surfactant [cetytrimethyl ammonium bromide (CTMAB), cetyl pyridine bromide (CPB), benzyl dimethyl dodecyl ammonium chloride (BDMDAC), and dodecyl trimethyl ammonium chloride (DTMAC)]. The surfactant could react with $\mathrm{Au}(\mathrm{CN})_{2}^{-}$to form the ionic complex, and the compound could be extracted by SPE column of reversed-phase bonded silica gel. Hence, a new method of SPE was proposed to extract gold with these features of the high selectivity, the reliability, and the simplicity. The experimental result shows that the recovery rate of gold is more than $98 \%$, and the solid-phase extraction column is not easily damaged and it can be repeatedly used. The new method can be used as the extraction process of gold from alkaline cyanide solution as well. Besides, the paper also puts forward a new process of gold extraction.
\end{abstract}

Keywords Solid-phase extraction; Surfactant; Alkaline cyanide solution; Gold; Mechanism

R.-F. Xie, Y.-H. Zhao, Z. Li*

School of Forensic Medicine, Kunming Medical University, Kunming 650500, China

e-mail: 755391400@qq.com

Q.-F. Hu, G.-Y. Yang, J. Chen

School of Chemical Science and Technology, Yunnan

University, Kunming 650091, China

Y.-S. Han

Inspection and Analysis Center, Yunnan Copper Industry

Limited by Share Ltd, Kunming 650102, China

\section{Introduction}

Cyanidation is the dominant process in the domestic and foreign gold extraction process. Therefore, the gold extraction from alkaline cyanide solution becomes a hot and difficult subject. The traditional methods used to extract gold from alkaline cyanide solution mainly contained the metal reduction method and the liquid-liquid extraction (LLE) method. However, these two methods have a lot of disadvantages, such as the serious environmental pollution, high cost, time consuming, low enrichment factor, consuming large amounts of organic solvent, prone to the third phase, etc.

Chen et al. proposed the approach of first adding quaternary ammonium surfactant into the alkaline cyanide solution, and then extracting gold with LLE method in the alkaline cyanide solution [1-8]. Although this method obtained a better result, it could not completely overcome the abovementioned disadvantages yet. Therefore, to our knowledge, the successful literatures concerning the field can rarely be found in domestic and foreign reports up to now.

The solid-phase extraction (SPE) technique was a kind of enrichment and separation technique [9-16]. The SPE technique possessed a lot of advantages in many areas. Particularly, the SPE column of the reversed-phase bonded silica gel was provided with the retention characteristics of the hydrophobic association. The characteristic was suitable for the enrichment of trace amounts substance in aqueous solution.

With regard to the SPE technique of reversed-phase bonded silica gel, the research mainly focused on the organic compound in the past. However, this kind of research was rarely used in inorganic compound. Based on Refs. [17-20], the authors proposed and explored the two types of techniques, namely the SPE and the LLE of the quaternary ammonium surfactant. The joint research of the 


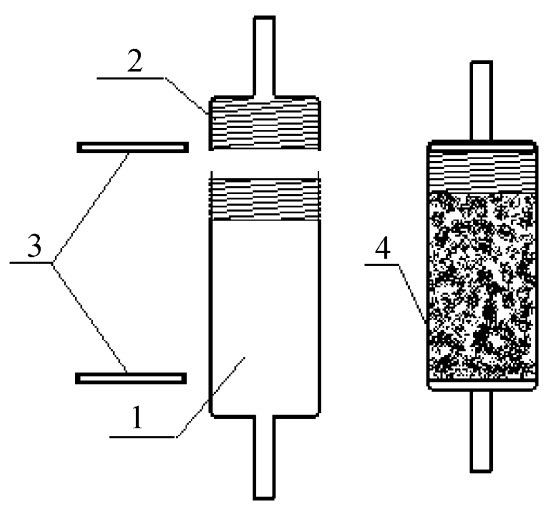

Fig. 1 Schematic diagram of SPE column with reversed-phase bonded silica gel. 1 Tube for filling resin; 2 screw cap for sealing tube; 3 sieve plate; 4 filler of reserved phase bonded silica gel

two types of techniques obtained satisfactory results, and we are looking forward to discovering some new highlights and enriching the knowledge of extraction chemistry in theory.

\section{Experimental}

\subsection{Apparatus}

SPE column is shown in Fig. 1 for the Sep-Pak ${ }^{\mathrm{R}}$ Cartridge (purchased from Waters Corporation, America). Each column was packed the filler of $0.33 \mathrm{~g}$ with reversed-phase bonded silica with $30 \mu \mathrm{m}$ particle size, with $\mathrm{pH}$ of $1-12$. The column must first pass through a certain amount of ethanol in order to activate, and then use distilled water to wash away the residual ethanol, and at last it could be used as sample extraction. The fillers of $C_{18}, C_{8}, C_{4}$, and $C_{2}$ columns are, respectively, octadecyl, octyl, butyl, and ethyl chemically bonded silica gel. The apparatus is as follows: UV-2401 ultraviolet spectrophotometer (Shimadzu Corporation, Tokyo, Japan); Beckman $\varphi 200$ pH meter (Beckman Instruments, Fullerton, CA, USA); the 8302 type of thermostatic water bath pot (Yuhua Instrument Factory, Gongyi, Henan, China)

\subsection{Reagent}

The $\mathrm{NaOH}$ solution of $\mathrm{pH} 10.5$ was prepared with the $\mathrm{NaOH}$ of analytical grade through dissolving with distilled water. The $\mathrm{NaOH}$ solution of $\mathrm{pH} 10.5$ was used as the preparation of all solutions.

A stock standard solution of gold $\left(2 \mathrm{~g} \cdot \mathrm{L}^{-1}\right.$, namely $C_{\mathrm{Au}}=0.01015 \mathrm{~mol} \cdot \mathrm{L}^{-1}$ ) was prepared with the $\mathrm{KAu}(\mathrm{CN})_{2}$ of analytical grade through dissolving with the preparation.
A working solution of gold $\left(50 \mu \mathrm{g} \cdot \mathrm{ml}^{-1}\right.$, namely, $C_{\mathrm{Au}}=2.538 \times 10^{-4} \mathrm{~mol} \cdot \mathrm{L}^{-1}$ ) was prepared through diluting the above stock standard solution with the preparation.

Cetytrimethyl ammonium bromide (CTMAB) solution $\left(0.01015 \mathrm{~mol} \cdot \mathrm{L}^{-1}\right)$ was prepared with the CTMAB of analytical grade through dissolving with the $\mathrm{NaOH}$ solution of $\mathrm{pH} 10.5$, and CTMAB solution $\left(2.538 \times 10^{-4} \mathrm{~mol} \cdot \mathrm{L}^{-1}\right)$ was prepared through diluting the above solution with the preparation.

Cetyl pyridine bromide (CPB) solution $\left(0.01015 \mathrm{~mol} \cdot \mathrm{L}^{-1}\right)$ was prepared with the $\mathrm{CPB}$ of analytical grade through dissolving with the $\mathrm{NaOH}$ solution of $\mathrm{pH} 10.5$, and CPB solution $\left(2.538 \times 10^{-4} \mathrm{~mol} \cdot \mathrm{L}^{-1}\right)$ was prepared through diluting the above solution with the preparation.

Benzyl dimethyl dodecyl ammonium chloride (BDMDAC) solution $\left(0.01015 \mathrm{~mol} \cdot \mathrm{L}^{-1}\right)$ was prepared with the BDMDAC of analytical grade through dissolving with the $\mathrm{NaOH}$ solution of $\mathrm{pH} 10.5$, and BDMDAC solution $\left(2.538 \times 10^{-4} \mathrm{~mol} \cdot \mathrm{L}^{-1}\right)$ was prepared through diluting the above solution with the preparation.

Dodecyl trimethyl ammonium chloride (DTMAC) solution $\left(0.01015 \mathrm{~mol} \cdot \mathrm{L}^{-1}\right)$ was prepared with the DTMAC of analytical grade through dissolving with the $\mathrm{NaOH}$ solution of $\mathrm{pH} 10.5$, and DTMAC solution $\left(2.538 \times 10^{-4} \mathrm{~mol} \cdot \mathrm{L}^{-1}\right)$ was prepared through diluting the above solution with the preparation.

The water used was once distilled water. The solid-phase column was the $C_{18}$ column (unless otherwise stated). The molar ratio of quaternary ammonium salt surfactant to $\mathrm{KAu}(\mathrm{CN})_{2}$ in the extracted solution under the experimental condition was 1.5:1.0. Namely, the calculated concentration of gold in the mixed solution was $20 \mu \mathrm{g} \cdot \mathrm{ml}^{-1}$ (unless otherwise stated).

\subsection{Procedure}

$20 \mathrm{ml}$ of $\mathrm{KAu}(\mathrm{CN})_{2}$ solution $\left(C_{\mathrm{Au}}=2.538 \times 10^{-4}\right.$ $\mathrm{mol} \cdot \mathrm{L}^{-1}$ ) was pipetted accurately into a $100 \mathrm{ml}$ Erlenmeyer flask, and then $30 \mathrm{ml}$ of quaternary ammonium surfactant solution $\left(C=2.538 \times 10^{-4} \mathrm{~mol} \cdot \mathrm{L}^{-1}\right)$ was added into the Erlenmeyer flask. Subsequently, the solution was mixed well and placed about $5 \mathrm{~min}$ at room temperature. The solution would pass through the SPE column at a flow rate of $15 \mathrm{ml} \cdot \mathrm{min}^{-1}$ (the SPE column must be loaded with a certain amounts of surfactant $\left(C=0.01015 \mathrm{~mol} \cdot \mathrm{L}^{-1}\right)$ before the sample passed through the column). After the enrichment was finished, the retained ionic complex was eluted from the column at a flow rate of $5 \mathrm{ml} \cdot \mathrm{min}^{-1}$ with $6.0 \mathrm{ml}$ of ethanol in the reverse direction. Two types of methods were used to calculate the recovery rate of gold. On the one hand, $1 \mathrm{ml}$ of SPE raffinate was accurately taken out, and subsequently digested cyanide with sulfuric acid 
and nitric acid, and the amount of gold was measured with malachite green spectrophotometry. The recovery rate of gold could be calculated according to the difference between the amounts of added gold and poured gold, that was divided by the amounts of added gold (if the SPE raffinate was not detected in gold, and it was considered that the gold was completely extracted). On the other hand, the determination of gold in the eluant also utilized malachite green spectrophotometry, but the ethanol in the eluant must be removed by evaporation before the cyanide in the eluant was digested with sulfuric acid and nitric acid. Otherwise, the ethanol in the eluant would cause explosion. According to the ratio of the amounts of measured gold to the added gold, the recovery rate of gold could be calculated. In this experiment, the two types of the methods of calculating recovery rate of gold can achieve mutual authentication purpose.

\section{Results and discussion}

\subsection{Effect of molar ratio of surfactant to Au on recovery rate of gold}

Some experiments were carried out in order to investigate the effect of the molar ratio of surfactant to $\mathrm{Au}$ on the recovery rate of gold. The surfactant [the molar ratio of (CTMAB, CPB, BDMDAC, and DTMAC): Au, respectively, acted as $0: 1 ; 0.25: 1 ; 0.50: 1 ; 0.75: 1 ; 1.00: 1 ; 1.25: 1$; $1.50: 1 ; 2.00: 1 ; 2.50: 1 ; 3: 1]$ was added into the samples. The results can be observed from Fig. 2. The recovery rate of gold increases after the surfactant was added into the samples, but the recovery rate of gold does not again increase when the molar ratio of surfactants to Au reaches to $1.25: 1.00$, and the recovery rate of gold reaches only about $60 \%$. However, if the solid-phase column was loaded with a certain amounts of surfactant $\left(C=0.01015 \mathrm{~mol} \cdot \mathrm{L}^{-1}\right)$ before the samples passed through the column, then the recovery rate of gold can reach above $98 \%$. Of course, the samples must be added proportionally into surfactant. So, the experimental condition is recommended that the molar ratio of surfactants to $\mathrm{Au}$ is 1.5:1.0, and the solid-phase column must be loaded with a certain amounts of surfactant $\left(C=0.01015 \mathrm{~mol} \cdot \mathrm{L}^{-1}\right)$ before the samples pass through the column.

\subsection{Effect of acidity}

According to Refs. [21-23], the condition of existence and stability of $\mathrm{Au}(\mathrm{CN})_{2}^{-}$was $\mathrm{pH}>9.4$, and the used acidity range of the SPE column was $\mathrm{pH} 1-12$. Therefore, some experiments were carried out in order to find the influence of the $\mathrm{pH}$ on the recovery rate of gold. The result shows that when the $\mathrm{pH}$ varies in the range of 9.5-12.0, the recovery rate of gold is all more than $98 \%$, and the change of $\mathrm{pH}$ does not affect the recovery rate of gold. Therefore, the experimental condition of $\mathrm{pH} 10.5$ is recommended considering the actual situation.

\subsection{Effect of flow rate of passing through column}

To investigate the effect of the flow rate of passing through the column on the recovery rate of gold, the result shows that the recovery rate of gold is all more than $98 \%$ when the flow rate of passing through column is less than $25 \mathrm{ml} \cdot \mathrm{min}^{-1}$. However, it begins to decline when the flow rate is more than $25 \mathrm{ml} \cdot \mathrm{min}^{-1}$. The conclusion can be drawn that the flow rate is so quick that the ionic complex, from which surfactant can react with $\mathrm{Au}(\mathrm{CN})_{2}^{-}$to form the ionic complex, cannot be completely adsorbed by the stationary phase. Therefore, the
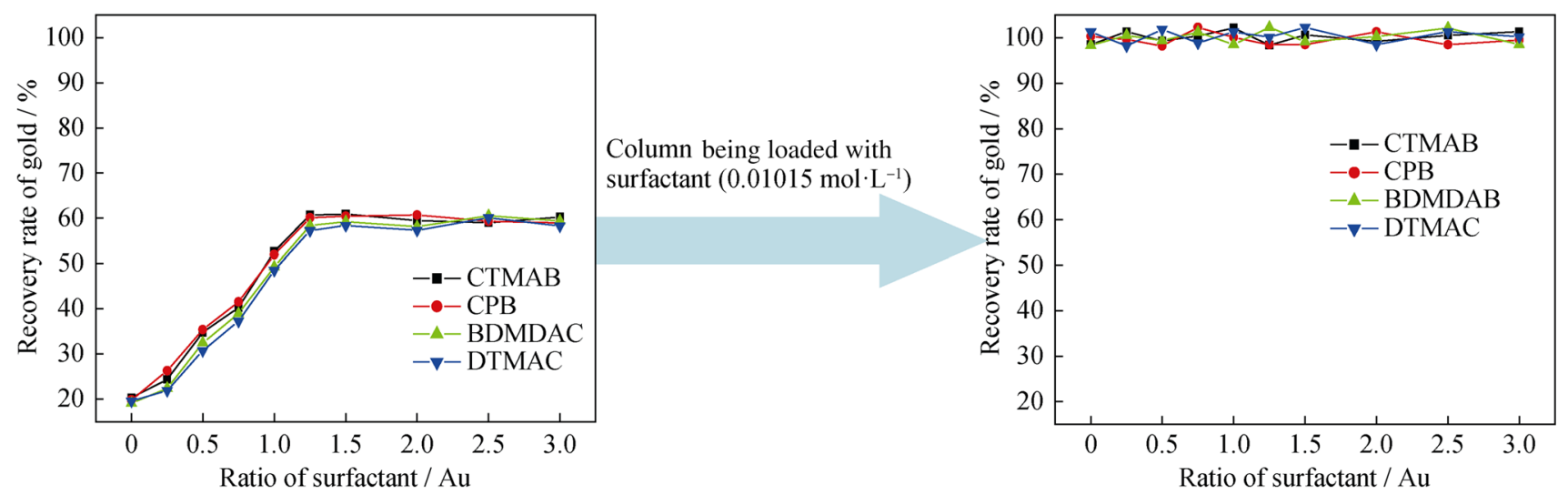

Fig. 2 Effect of surfactant/Au mole ratio on recovery rate of gold 
ionic complex flows out the stationary phase for lacking of enough time, which leads to the decrease of the recovery rate of gold. At the same time, the flow rate of passing through column is closely related with the pressure of passing through column. The $15 \mathrm{ml} \cdot \mathrm{min}^{-1}$ of the flow rate of passing through the column is selected as the flow rate of passing through column.

\subsection{Determination of extraction capacity of SPE column with different fillers}

\subsubsection{Determination of maximum extraction capacity of $C_{18}$ column}

$20 \mathrm{ml}$ of $\mathrm{KAu}(\mathrm{CN})_{2}$ solution $\left(50 \mu \mathrm{g} \cdot \mathrm{ml}^{-1}\right.$, namely $\left.C_{\mathrm{Au}}=2.538 \times 10^{-4} \mathrm{~mol} \cdot \mathrm{L}^{-1}\right)$ and the $30 \mathrm{ml}$ of surfactant solution $\left(C=2.538 \times 10^{-4} \mathrm{~mol} \cdot \mathrm{L}^{-1}\right)$ were put accurately in a $100 \mathrm{ml}$ Erlenmeyer flask, and then the solution was mixed. In this procedure, usually a lot of the solutions were prepared. Each solution passed through $C_{18}$ column at the flow rate of $15 \mathrm{ml} \cdot \mathrm{min}^{-1}$. The volume passing through the column of each surfactant of CTMAB, CPB, BDMDAC, and DTMAC exceeded to $1300,1250,850$, and $200 \mathrm{ml}$, respectively; then, the gold begins to leak from the SPE column, which is considered that the extraction column reaches the saturation of gold extraction. Therefore, the maximum extraction capacities of CTMAB, CPB, BDMDAC, and DTMAC are, respectively, 26, 25, 17, and $4 \mathrm{mg}$ by calculating. The extraction capacities of $C_{18}$ column of CTMAB, CPB, BDMDAC, and DTMAC were controlled in $23,23,14$, and $3 \mathrm{mg}$, respectively, because the extraction capacity cannot exceed the maximum extraction capacity, as shown in Tables 1 and 2.

\subsubsection{Determination of maximum extraction capacity of $C_{8}, C_{4}, C_{2}$ columns}

The method of operation is the same as the one described above in Sect. 3.4.1. In this paper, the maximum extraction capacities of $C_{8}, C_{4}, C_{2}$ column were explored. The results are shown in Table 1 . The conclusion can safely be drawn that the maximum extraction capacity of column declines with the descending in the order of the length of alkyl chain of surfactant, and the maximum extraction capacity of $C_{18}$ column is the highest among the four kinds of the experimental surfactant. Therefore, the column of $C_{18}$ and the surfactant of CTMAB are recommended, because the surfactant with chloridizing is cheaper than that with bromide. Moreover, the column of $\mathrm{C}_{18}$ is easy to be purchased.

Table 1 Extraction capacity of solid-phase extraction column with different columns (mg)

\begin{tabular}{lrrrl}
\hline $\begin{array}{l}\text { Types of quaternary } \\
\text { ammonium surfactant }\end{array}$ & $C_{18}$ & $C_{8}$ & $C_{4}$ & $C_{2}$ \\
\hline CTMAB & 26 & 22 & 23 & 20 \\
CPB & 25 & 23 & 24 & 20.5 \\
BDMDAC & 17 & 13 & 8 & 5 \\
DTMAC & 4 & 4 & 4 & 4 \\
\hline
\end{tabular}

Recovery rate of gold being all more than $98 \%$

Table 2 Recovery rate of different initial gold concentrations

\begin{tabular}{|c|c|c|c|c|}
\hline \multirow[t]{3}{*}{ Concentration of gold $/\left(\mu \mathrm{g} \cdot \mathrm{ml}^{-1}\right)$} & \multicolumn{4}{|c|}{ Enrichment factor } \\
\hline & \multicolumn{2}{|c|}{$\begin{array}{l}23 \mathrm{mg} \text { enrichment amounts } \\
\text { of gold, } 6 \mathrm{ml} \text { of ethanol } \\
\text { eluent }\end{array}$} & \multirow{2}{*}{$\begin{array}{l}14 \mathrm{mg} \text { enrichment amounts of gold, } \\
4 \mathrm{ml} \text { of ethanol eluent } \\
\text { BDMDAC }\end{array}$} & \multirow{2}{*}{$\begin{array}{l}3 \mathrm{mg} \text { enrichment amounts of gold, } \\
3 \mathrm{ml} \text { of ethanol eluent } \\
\text { DTMAC }\end{array}$} \\
\hline & CTMAB & $\mathrm{CPB}$ & & \\
\hline 2 & 1,916 & 1,916 & 1,750 & 500 \\
\hline 5 & 766 & 766 & 700 & 200 \\
\hline 10 & 383 & 383 & 350 & 100 \\
\hline 15 & 255 & 255 & 233 & 66 \\
\hline 20 & 191 & 191 & 175 & 50 \\
\hline 25 & 153 & 153 & 140 & 40 \\
\hline 30 & 127 & 127 & 116 & 33 \\
\hline 35 & 109 & 109 & 100 & 28 \\
\hline 40 & 95 & 95 & 87 & 25 \\
\hline 45 & 85 & 85 & 77 & 22 \\
\hline 50 & 76 & 76 & 70 & 20 \\
\hline Average recovery rate of gold ( $\%$ ) & 99.91 & 100.57 & 100.08 & 100.43 \\
\hline
\end{tabular}

Enrichment amounts of $C_{18}$ column cannot exceed maximum extraction capacity of $C_{18}$ column described in Table 1 . Therefore, enrichment amounts of gold being less than maximum extraction capacity of $C_{18}$ column 
3.5 Effect of eluant, volume of eluent, and flow rate of eluting

The eluant, mainly methanol, ethanol, acetonitrile, acetone and tetrahydrofuran, could completely elute the enriched ionic complex. Because of the less toxicity, the weaker volatile and the cheaper price of ethanol, it is selected as the eluant.

The volume of the eluant is seriously related to the amounts of the enriched ionic complex and the flow rate of eluting. It is to say that the more the enriched ionic complex is, the more the eluant is needed. At the same time, the faster the flow rate of eluting is, the more the eluant is required. When the enrichment amounts of gold are 23, 23, 14 , and $3 \mathrm{mg}$, respectively, the volume of eluant required could be $6,6,4$, and $3 \mathrm{ml}$, respectively, as exhibited in Table 2. The experiment also recommends that the flow rate of eluting should be $5 \mathrm{ml} \cdot \mathrm{min}^{-1}$, considering the enrichment factor and the elution time.

\subsection{Mechanism of reversed-phase SPE and enrichment gold}

\subsubsection{Mechanism of reversed-phase SPE process}

Reversed-phase SPE is a liquid-solid extraction mode, which is established on the base of the hydrophobic characteristics of surface among the solute, the polar mobile phases, and the nonpolar stationary phase. The extraction process is a physical extraction process, which includes liquid phase and solid phase. In the course of extraction, the adsorption of the solid phase for the solute is greater than that of the solvent, when the sample passes through the solid-phase column, and the solute with hydrophobic groups can be retained in the column. The stronger the hydrophobic property of the hydrophobic groups of the solute is, the bigger the retention value of the solute is.

In fact, the $\mathrm{Au}(\mathrm{CN})_{2}^{-}$that has no hydrophobic property cannot be extracted directly by reversing phase stationary phase. However, when quaternary ammonium surfactant was added into the solution with the $\mathrm{Au}(\mathrm{CN})_{2}^{-}$, they could react each other to form the ionic complex with hydrophobic property [24-26]. The ionic complex in aqueous solution, which passed through the reversed-phase SPE column, could be adsorbed in the reversed-phase SPE column because the adsorption of the stationary phase is stronger than that of the water solvent.

\subsubsection{Mechanism of eluting process}

During the elution process, because the adsorption of reversed-phase stationary phase for the enriched ionic complex is less than the adsorption of the eluent for the ionic complex, the enriched ionic complex is eluted down $[27,28]$. In this experiment, when the pure organic solvent was used as an eluent, the eluting efficiency of the eluent declines with the enhancement of the polarity of the eluent (methanol $<$ ethanol $<$ acetonitrile $<$ acetone $<$ tetrahydrofuran). When the mixed solution of polar organic solvent and water was used as an eluent, the higher the organic solvent proportion of the eluent is, the stronger the eluting efficiency of the eluent is.

\subsection{Recovery rate of different initial gold concentration}

Referring to the concentration of the mining actual sample, the influence of the different initial gold concentrations on the recovery rate of gold was tested. The results are shown in Table 2. The conclusion can be drawn that different initial gold concentrations have no effect on the recovery rate of gold, and the recovery rate is more than $98 \%$. Table 2 also shows that the enrichment factor of the low concentration sample is higher, and the enrichment factor achieves to 1,916 times. This means that the SPE technique has obvious advantage on the low concentration sample.

\subsection{Interference of coexisting ions}

In order to investigate the selectivity of the method, some experiments were done to observe whether there are some influences of coexisting ions on gold extraction or not. The result shows that under the conditions, such as $C_{\mathrm{Au}}=5 \mu \mathrm{g} \cdot \mathrm{ml}^{-1}$ and the concentration of the coexisting ions $\left(\mathrm{M}^{+n}\left(\mathrm{mg} \cdot \mathrm{ml}^{-1}\right)\right)$, which are $\left[\mathrm{Na}^{+}, \mathrm{Mg}^{2+}, \mathrm{K}^{+}, \mathrm{Ca}^{2+}\right.$, $\mathrm{NH}_{4}{ }^{+}(25) ; \mathrm{V}(\mathrm{V}), \mathrm{Ni}^{2+}, \mathrm{PO}_{4}^{3-}, \mathrm{SO}_{4}^{2-}, \mathrm{Al}^{3+}(7) ; \mathrm{Fe}^{3+}, \mathrm{Co}^{2+}$, $\mathrm{Mo}(\mathrm{VI}), \mathrm{Mn}^{2+}, \mathrm{SiO}_{3}{ }^{2-}(4) ; \mathrm{Cr}^{3+}, \mathrm{W}(\mathrm{VI}), \mathrm{Ti}(\mathrm{IV})(0.8)$; $\mathrm{Sn}(\mathrm{VI}), \mathrm{Cd}^{2+}$, As(V), $\mathrm{Zn}^{2+}(0.2) ; \mathrm{Hg}^{2+}, \mathrm{Cu}^{2+}(0.1) ; \mathrm{Ag}^{+}$, $\left.\mathrm{Pb}^{2+}(0.04) ; \mathrm{Pt}(\mathrm{IV})(0.008) ; \mathrm{Pd}^{2+}(0.005)\right]$, these coexisting ions have no influence on the extraction of gold. The recovery rate of gold is more than that of $98 \%$. The method has high selectivity.

\subsection{Determination and results of samples}

In order to verify the reliability, reproducibility and accuracy of the method, six actual samples (low, medium, high concentration of gold in cyanide solution) were measured with the proposed method. The determination result of the method was compared with the determination result of the atomic absorption spectrophotometry. The results are exhibited in Table 3. It can be observed from Table 3 that the relative deviation is less than $10 \%$, the relative standard deviation $(R S D)$ is less than $5 \%$, and the recovery rate of gold is greater than $98 \%$. It can be drawn the conclusion that the method in this paper is reliable, reproducible, and accurate. 
Table 3 Analytical results of samples $(n=5)$

\begin{tabular}{|c|c|c|c|c|c|}
\hline \multirow[t]{2}{*}{ Samples* } & \multicolumn{5}{|c|}{ Concentration of gold in cyanide solution $\left(\mu \mathrm{g} \cdot \mathrm{ml}^{-1}\right)$} \\
\hline & $\begin{array}{l}\text { Atomic absorption spectrophotometry } \\
\text { (AAS)* }\end{array}$ & СТMAB & $\mathrm{CPB}$ & BDMDAC & DTMAC \\
\hline YT 0216 & 5.24 & 4.87 & 5.79 & 5.71 & 4.82 \\
\hline YT 0249 & 4.68 & 5.02 & 5.06 & 4.24 & 4.93 \\
\hline YT 0302 & 24.53 & 24.95 & 22.62 & 25.38 & 23.15 \\
\hline YT 0345 & 26.37 & 25.92 & 27.94 & 24.97 & 24.96 \\
\hline YT 0369 & 48.95 & 50.59 & 45.78 & 50.13 & 46.82 \\
\hline YT 0387 & 47.62 & 49.14 & 50.13 & 45.86 & 50.97 \\
\hline $\begin{array}{l}\text { Relative deviation of compared with AAS method/ } \\
\%\end{array}$ & - & 5.34 & 7.25 & 5.58 & 6.01 \\
\hline$R S D / \%$ & - & 2.81 & 4.12 & 2.94 & 3.95 \\
\hline Recovery rate (adding standard Au $5 \mu \mathrm{g} \cdot \mathrm{ml}^{-1}$ )/ \% & - & 98.76 & 101.33 & 100.22 & 99.81 \\
\hline
\end{tabular}

* Samples and measurement value of AAS method being provided by Inspection and Analysis Center of Yunnan Copper Industry Limited by Share Ltd of China

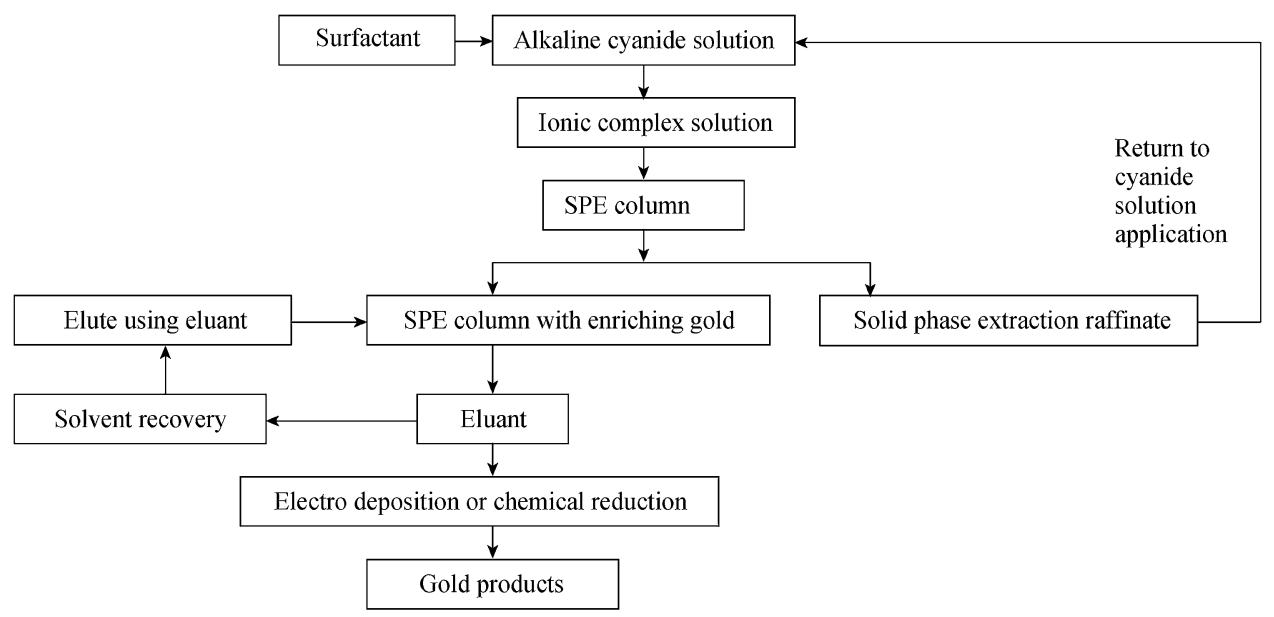

Fig. 3 Process flow diagram of solid-phase extraction of gold

\subsection{Process flow diagram of solid-phase extraction of gold}

Based on the experimental results and the experimental phenomena, the authors propose a new process of separation and preconcentration of gold from alkaline cyanide solution, as shown in Fig. 3. If the expansion test can be successful, then it will provide a possibility of the extraction of the low-content gold ore. The new process implies an important significance.

\section{Conclusion}

This paper demonstrates the successful extraction and enrichment gold from alkaline cyanide solution with SPE (initial gold concentration ranges from 5 to $50 \mu \mathrm{g} \cdot \mathrm{ml}^{-1}$ as the simulated samples). The recovery rate of gold is higher than $98 \%$. The newly established method not only applies to the pretreatment of the sample, but also the new process of gold extraction from alkaline cyanide solution. The method is verified what is reliable, reproducible, and accurate, which determines the six low, medium, high concentration actual samples by comparing with the new method's analytical result with the determination result of the atomic absorption spectrophotometry. The new method is of high selectivity by determining the interference of coexisting ions. The method solves the common problem, i.e., the more and more difficult pretreatment of the sample. The new method can also be used as the extraction process of gold from alkaline cyanide solution. Therefore, a new process of gold extraction was put forward. The extraction efficiency of surfactant is in such an order $($ CTMAB $\approx \mathrm{CPB}>\mathrm{BDMDAC}>\mathrm{DTMAC})$. The extraction capacity of the SPE column, which excludes the 
surfactant of DTMAC, is in such a subsequence $\left(C_{18}>C_{8}>\right.$ $C_{4}>C_{2}$ ). Therefore, the paper recommends the surfactant CTMAB and $C_{18}$ column, according to their economic and easily purchasing characteristics.

Acknowledgments This study was financially supported by the National Natural Science Foundation of China (No. 20471051.).

Open Access This article is distributed under the terms of the Creative Commons Attribution License which permits any use, distribution, and reproduction in any medium, provided the original author(s) and the source are credited.

\section{References}

[1] Yang XJ, Chen J, Xie QY, Wu JG. Solvent extraction of gold from alkaline aurocyanide solutions by cationic surfactants. Prog Chem. 2007;23(1):57.

[2] Chen B, Liu FS. Phase transformation behavior and mechanical properties of $\mathrm{Ti}_{50} \mathrm{Ni}_{49-x} \mathrm{Fe}_{1} \mathrm{Co}_{x}$ shape memory alloys. Rare Met. 2013;32(3):225.

[3] Zou LH, Chen J. The application of solvent recovery from alkaline extraction on the gold cyanide solutions. Precious Met. 1995;16(4):61.

[4] Liu YC, Zhu ZS, Fu JG, Li LF, Lin QQ, Li ZH. Leaching gold ores by lime-sulphur-synthetic-solution with alkali-catalyzed process. Chin J Rare Met. 2013;37(1):123.

[5] Huang K, Chen J, Wu JG, Gao HC, Cui N, Yu JM. Effects of modifiers on $\mathrm{Au}(\mathrm{CN})_{2}^{-}$solvent extraction by CTMAB. Chin J Nonferrous Met. 2001;11(2):307.

[6] Huang K, Chen J, Cui N, Wu JG, Zhou WJ, Yan WF. Abnormal influence of salting-out agent on $\mathrm{Au}(\mathrm{CN})_{2}^{-}$solvent extraction by CTMAB. Chin J Nonferrous Met. 2001;11(3):518.

[7] Yang XZ, Hao ZY, Yang ZX, Lin HK, Hu QF. Solid phase extraction for separation of palladium by dimethyl sulfoxide system. Chin J Rare Met. 2013;37(5):814.

[8] Yang JL, Liu QJ, Guo YH, Xiao H, Jiang MG. Low grade nonindependent copper oxide ore and associated gold comprehensive recovery. Chin J Rare Met. 2013;37(4):666.

[9] Wu FH. Study of new technology on solid phase extraction. Anal Test Technol Instrum. 2012;18(2):114.

[10] Zhang HX, Zhu PL. Solid phase extraction. Chin J Anal Chem. 2000;28(9):1172.

[11] Racamonde I, Rodil R, Quintana JB, Cela R. In-sample derivatization-solid-phase microextraction of amphetamines and ecstasy related stimulants from water and urine. Anal Chim Acta. 2013;770:75.

[12] Choi H, Baeck S, Jang M, Lee S, Choi H, Chung H. Simultaneous analysis of psychotropic phenylalkylamines in oral fluid by GC-MS with automated SPE and its application to legal cases. Forensic Sci Int. 2012;215(1-3):81.

[13] Dobos A, Hidvegi E, Somogyi GP. Comparison of five derivatizing agents for the determination of amphetamine-type stimulants in Human urine by extractive acylation and gas chromatographymass spectrometry. J Anal Toxicol. 2012;36(5):340.
[14] Abe E, Ricard F, Darrouzain F. An automated method for measurement of methoxetamine in Human plasma by use of turbulent flow on-line extraction coupled with liquid chromatography and mass spectrometric detection. Anal Bioanal Chem. 2013;405: 239.

[15] Donata F, Vogliardi S, Stocchero G, Nalesso A, Tucci M, Terranova C, Ferrara SD. Determination of ketamine and norketamine in hair by micropulverized extraction and liquid chromatographyhigh resolution mass spectrometry. Forensic Sci Int. 2013; 226(1-3):88.

[16] Li L, Leopold K. Ligand-assisted extraction for separation and preconcentration of gold nanoparticles from waters. Anal Chem. 2012;84(10):4340.

[17] Hu QF, Chen XB, Yang XJ, Huang ZJ, Chen J, Yang GY. Solid phase extraction and spectrophotometric determination of $\mathrm{Au}(\mathrm{III})$ with 5-(2-hydroxy-5-nitrophenylazo) thiorhodanine. Anal Sci. 2006;22(4):627.

[18] Yang GY, Hu QF, Yang JH, Huang ZJ, Yin JY. Solid phase extraction and spectrophotometric determination of silver with 2-(2-quinolylazo)-5-diethylaminophenol as chromogenic reagent. Anal Sci. 2003;19(2):299.

[19] Rajesh N, Gurulakshmanan G. Solid phase extraction and spectrophotometric determination of mercury by adsorption of its diphenylthiocarbazone complex on an alumina column. Spectrochim Acta Part A. 2008;69(2):391.

[20] Amin AS, Saber AL, Mohammed TY. Study on solid phase extraction and spectrophotometric determination of vanadium with 2,3-dichloro-6-(2,7-dihydroxy-1-naphthylazo) quinoxaline. Spectrochim Acta Part A. 2009;73(1):195.

[21] Xie QY, Chen J, Yang XJ. Effect of $\mathrm{HCl}$ Concentration on formation of third-phase in $\mathrm{N}_{235}-\mathrm{C}_{12} \mathrm{H}_{26}-\mathrm{HCl}$ solvent extraction system. Chin J Inorg Chem. 2008;24(6):897.

[22] Liu YY, Chen J, Xie QY. Effect factors of third phase produced by $\mathrm{N}_{235}$ extracting $\mathrm{Pt}$ system. Chin $\mathrm{J}$ Nonferrous Met. 2009;19(7):1316.

[23] Xie QY, Chen J, Yang XJ, Wang Y. Mechanism of third-phase elimination by TBP in $\mathrm{N} 235 / \mathrm{HCl}$ solvent extraction system. Chin J Inorg Chem. 2007;23(1):57.

[24] Sun HW, Qiao FX. Recognition mechanism of water-compatible molecularly imprinted solid-phase extraction and determination of nine quinolones in urine by high performance liquid chromatography. J Chromatogr A. 2008;1212(1-2):1.

[25] Xie F, Dreisinger D. Studies on solvent extraction of copper and cyanide from waste cyanide solution. J Hazard Mater. 2009;169 (1-3):333.

[26] Kocúrová L, Balogh IS, Skrlíková J, Postac J, Andruch V. A novel approach in dispersive liquid-liquid microextraction based on the use of an auxiliary solvent for adjustment of density UV-Vis spectrophotometric and graphite furnace atomic absorption spectrometric determination of gold based on ion pair formation. Talanta. 2010;82(5):1958.

[27] Jamt REG, Gjelstad A, Eibak LE, Qiestad EL, Christophersen AS, Rasmussen KE, Pedersen-Bjergaard ST. Electromembrane extraction of stimulating drugs from undiluted whole blood. J Chromatogr A. 2012;1232:27.

[28] Ghaedi M, Parham H, Moghadam M, Mortazavi K, Soylak M. Solid phase extraction and spectrophotometric determination of trace amounts of thiocyanate in samples. Anal Chim. 2006; 96(11-12):689. 